\title{
IMPROVING SOCIAL SCIENCES LEARNING OUTCOMES THROUGH ONLINE LEARNING AT SDN 005 KEMPAS JAYA
}

\author{
Syafri Efnedi \\ SDN 005 Kempas Jaya, Indragiri Hilir, Indonesia \\ syafriefnedi@gmail.com
}

\begin{abstract}
The purpose of this study was to improve social studies learning outcomes through online learning. This research was a collaborative classroom action research $(C A R)$ in which teachers and researchers worked together in order to improve the learning outcomes of fourth grade students at SDN 005 Kempas Jaya, Kecamatan Kempas, Kabupaten Indragiri Hilir. The results of this study showed that the percentage of teachers' activities in online learning in Cycle I meeting 1 was $76 \%$ and it increased in meeting II to 76.16\%. Meanwhile, in Cycle II, the percentage of activities at meeting I was $80.33 \%$ and it increased to $85.5 \%$ at meeting II. It was observed that the teacher's activities carried out in online learning on social studies subject increased the students'social studies learning outcome. It was seen from the average initial score (before implementing online learning) shwoed only 56.53; at the end of Cycle I, the average score of student learning outcomes increased to 65.77 with an increase of 9.24 points. It was found that the students were still not familiar with the impekemntation of online learning in Cycle I since this learning provided more opportunities for students to be able to use technology, especially smartphones, as a learning tool. Meanwhile, at the end of the test in Cyle II, the average score of students' learning outcomes increased to 69.03 with an increase of 12.5 points. There has been an increase in students' learning outcomes by implementing online learning
\end{abstract}

Keywords: learning outcomes, online learning

\section{MENINGKATKAN HASIL BELAJAR IPS DENGAN PEMBELAJARAN DARING DI SDN 005 KEMPAS JAYA}

\begin{abstract}
ABSTRAK
Tujuan penelitian ini untuk meningkatkan hasil belajar IPS dengan melakukan pembelajaran daring. Penelitian ini merupakan penelitian tindakan kelas (PTK) kolaboratif yaitu guru dan peneliti bekerjasama. Penelitian tindakan/ usaha di dalam proses pembelajaran guna meningkatkan hasil belajar siswa kelas IV SDN 005 Kempas Jaya Kecamatan Kempas Kabupaten Indragiri Hilir. Hasil penelitian ini bahwa aktivitas guru dalam pembelajaran daring pada siklus I pertemuan 1 dengan hasil $76 \%$ meningkat pada pertemuan kedua $76.16 \%$, pada siklus II dengan persentase kegiatan pada pertemuan pertama sebesar $80.33 \%$ meningkat menjadi $85.5 \%$ pada pertemuan kedua. Terlihat aktivitas guru yang dilakukan dalam pembelajaran daring pada mata pelajaran IPS dengan dilakukan ujian ulangan dengan hasil belajar IPS siswa dengan menerapkan pembelajaran daring mengalami peningkatan, yang dimulai dari skor dasar atau sebelum menerapkan pembelajaran daring rata-rata hasil belajar IPS yang diperoleh siswa hanya 56.53, pada ulangan akhir siklus pertama nilai rata-rata hasil belajar siswa meningkat akhir siklus pertama nilai rata-rata hasil siswa meningkat menjadi 65.77 dengan peningkatan 9.24 poin. Bila diperhatikan kondisi hasil belajar siswa pada skor dasar dan ulangan akhir siklus pertama, karena siswa masih belum terbiasa dengan menerapkan pembelajaran daring karena pembelajaran ini lebih memberikan kesempatan kepada siswa untuk mampu menggunakan teknologi berupa smartphone sebagai alat pembelajaran. Sementara itu pada ulangan akhir siklus kedua, nilai rata-rata hasil belajar siswa meningkat menjadi 69.03 dengan peningkatan sebesar 12.5 poin. Terjadi peningkatan hasil belajar siswa dengan menerapkan pembelajaran daring.
\end{abstract}

Kata Kunci: hasil belajar, pembelajaran daring

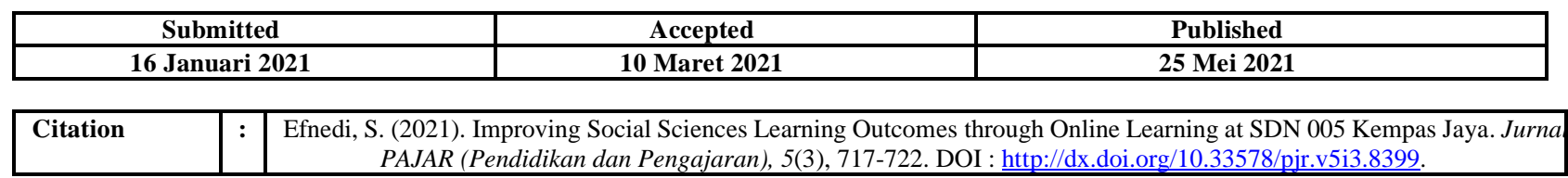

\section{PENDAHULUAN}

Pentingnya belajar IPS ini, maka mengajarkan IPS perlu ditingkatkan agar tujuan pembelajaran IPS dapat tercapai. Adapun tujuan pembelajaran IPS diantaranya adalah 1) Memiliki

sikap patriotisme, yaitu cinta tanah air bangsa dan negara, 2) Mempunyai penghargaan dan pengertian terhadap nilai-nilai, pranata dan praktik kehidupan kemasyarakatan, 3) Memiliki sikap 
integritas sosial dan tanggung jawab sebagai warga negara, 4) mempunyai pengetian dan penghargaan terhadap nilai-nilai budaya atau tradisi yang diwariskan oleh bangsanya, 5) Mempunyai motivasi untuk turut secara aktif dalam pelaksanaan kehidupan demokratis, 6) Memiliki kesadaran (tanggap akan) masalahmasalah sosial, 7) Memiliki ide, sikap dan keterampilan yang diharapkan sebagai seorang warga negara, 8) Mempunyai pengertian dan penghargaan terhadap sistem ekonomi yang berlaku (Yuliati, 2008). Kegiatan pembelajaran yang dilaksanakan guru merupakan proses membimbing kegiatan belajar siswa dan membelajarkan siswa, sehingga apa yang dipelajari menjadi bermakna bagi siswa (Azimah, \& Kurniaman, 2019). Proses belajar pada dasarnya bertujuan agar siswa mampu mengembangkan pengetahuan dan keterampilan dasar yang berguna bagi dirinya dalam kehidupan sehari-hari untuk mengarahkan anak didik pada tujuan akhir dengan hasil baik (Saputra, \& Prasetyono, 2020).

Pada abad 21 pembelajaran tidak bisa terlepas dari dunia digital, salah satunya kemajuan teknologi yang memberikan inovasi-inovasi baru untuk memudahkan guru dalam menjalankan pembelajaran di kelas ( Mukmin, \& Zunaidah, 2018). Kemajuan tersebut juga berpengaruh pada dunia pendidikan yang saat ini sedang mengalami pandemik seluruh dunia yang mampu memberikan pembelajaran baru dengan nuansa baru dalam pembelajaran (Rambe, 2019). Pandemi Covid-19 ini telah mengubah pola pembelajaran yang semestinya tatap muka menjadi pembelajaran daring (dalam jaringan). Sebelum adanya situasi ini, tidak banyak waktu orang tua dalam membimbing anaknya, bahkan sampai orang tua hanya sekedar sebagai pemenuhan kebutuhan materi saja (Cahyani, Ismaya, \& Fajrie, 2021). Peran orang tua dalam pembelajaran daring ini lebih optimal untuk membimbing siswa serta mendampingi mereka dalam belajar.

Perubahan kegiatan belajar dari ruang kelas kerumah membawa tantangan baru. Kesiapan guru, siswa dan orang tua dalam pembelajaran di rumah ini bervariasi, ada yang siap, dipaksa untuk siap, dan benar-benar tidak siap. Tanpa persiapan, akan sulit bagi orang tua dan anak untuk beradaptasi dengan perubahan sistem dari tatap muka menjadi online dengan memanfaatkan teknologi (Novianti, Puspitasari, \& Maria, 2021). Pembelajaran daring ini merupakan arternatif dalam pembelajaran di sekolah dasar dalam meningkatkan hasil belajar IPS. Walaupun terhalang oleh jaringan atau tatap muka yang tidak bisa dilakukan maka dalam pembelajaran IPS ini tetap menekankan pada kejujuran, dan profesionalisme siswa tetap membuka video supaya guru mampu mengontrol sehingga bisa dilaksanakan pembelajaran dengan efektif (Buchori, \& Setyawati, 2015).

\section{METODE PENELITIAN}

Bentuk penelitian ini merupakan penelitian tindakan kelas (PTK) kolaboratif yaitu guru dan peneliti bekerjasama. Penelitian tindakan/ usaha di dalam proses pembelajaran guna meningkatkan hasil belajar siswa (Borg, \& Gall, 1983). Dalam melakukan penelitian ini dilakukan secara kolaboratif antara guru dengan peneliti yang berperan sebagai pelaksana pembelajaran selama proses pembelajaran (Arikunto, 2009). 
Jurnal PAJAR (Pendidikan dan Pengajaran)

Volume 5 Nomor 3 April 2021 | ISSN Cetak : 2580 - 8435 | ISSN Online : 2614 - 1337

DOI : http://dx.doi.org/10.33578/pjr.v5i3.8399

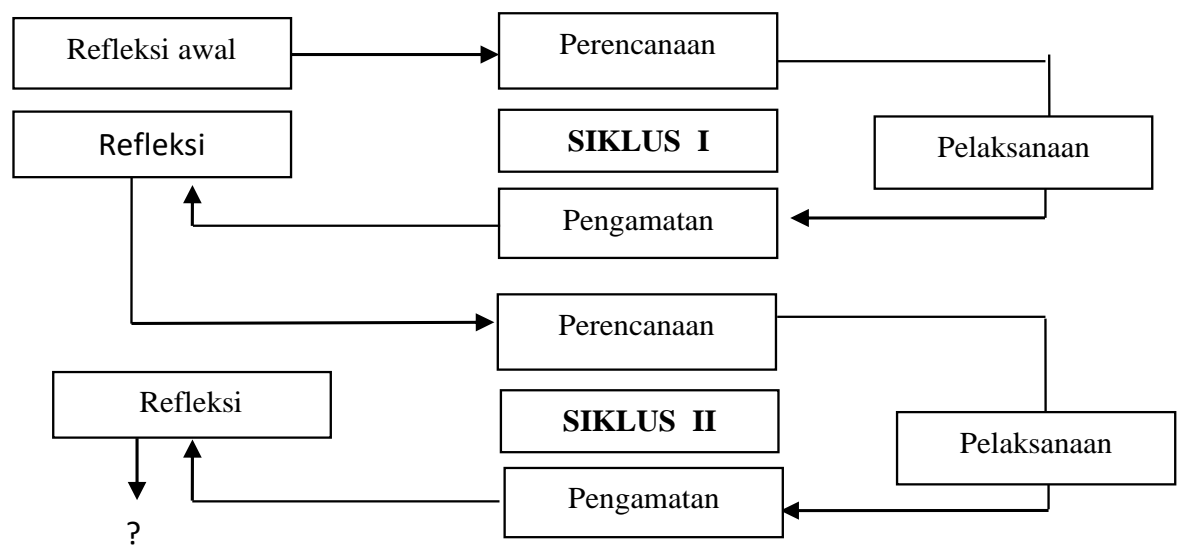

Gambar 1. Siklus PTK (Arikunto, 2009)

Lokasi penelitian ini dilaksanakan di SDN 005 Kempas Jaya Kecamatan Kempas Kabupaten Indragiri Hilir, di kelas IV dengan jumlah siswa laki-laki 17 orang, dan perempuan 13 orang. Dalam PTK ini peneliti merencanakan dua siklus. Siklus pertama diawali dengan refleksi awal karena peneliti telah memiliki data yang dapat dijadikan dasar untuk merumuskan tema, penelitian yang selanjutnya diikuti perencanaan tindakan, pelaksanaan tindakan dan refleksi. Berdasarkan hasil refleksi siklus pertama dilakukan perbaikan pada siklus berikutnya.

Secara garis besar penelitian tindakan kelas dilaksanakan melalui 4 tahap yang biasa dilalui yaitu : a) perencanaan, b) pelaksanaan, c) pengamatan, d) refleksi. Berikut penjelasan tahaptahap dalam PTK yaitu :

1) Perencanaan

Tahap ini peneliti merencanakan tentang apa, mengapa dimana, siapa dan bagaimana tindakan yang akan diadakan untuk perbaikan proses pembelajaran perencanaan berisikan LKS.

2) Pelaksanaan Tindakan

Pelaksanaan tindakan merupakan implementasi dari perencanaan atau penerapan isi rancangan

3) Pengamatan

Pengamatan ini dilakukan oleh pengamat.

Pengamatan dilakukan pada waktu tindakan dengan menggunakan lembar pengamatan

4) Refleksi
Kegiatan merenungkan kembali proses pembelajaran yang telah dilakukan dalam rangka mencari kelemahan-kelemahan dalam pembelajaran yang akan diperbaiki pada pertemuan berikutnya.

Teknik pengumpulan data dalam penelitian ini dengan melakukan dua teknik yaitu 1) teknik observasi digunakan untuk mengetahui kesesuaian pelaksanaan tindakan dengan rencana tindakan yang telah disusun sebelumnya, dan untuk mengetahui seberapa jauh pelaksanaan tindakan yang sedang dilakukan pelaksanaan tindakan diharapkan akan menghasilkan perubahan yang diinginkan. 2) teknik tes yang bertujuan untuk mengukur dan mengetahui sejauh mana tingkat penguasaan anak terhadap materi yang diajarkan. Dengan melakukan ulangan harian dua kali yaitu ulangan harian 1 dan ulangan harian II. Ulangan harian I dapat dilakukan setelah siklus pertama selesai, begitu juga dengan pelaksanaan ulangan harian II setelah siklus kedua selesai.

Data yang diperoleh pada penelitian ini selanjutnya dianalisis untuk mengetahui aktifitas guru dan siswa selama proses pembelajaran dan sejauh mana ketercapaian Standar Kriteria Ketuntasan Minimal yang telah ditetapkan. Data yang telah diperoleh dianalisis secara deskriptif. Teknik analisis deskriptif bertujuan untuk menggambarkan data aktivitas guru dan siswa selama proses pembelajaran dan data ketercapaian kompetensi dasar. Pelaksanaan dikatakan berhasil 
jika $\geq 75 \%$ dari semua aktivitas guru dan siswa pada pembelajaran berlangsung tertuang dalam skenario pembelajaran dan terlaksana dengan sendirinya.

\section{HASIL DAN PEMBAHASAN}

Penelitian Tindakan Kelas (PTK) ini dilaksanakan di SDN 005 Kempas Jaya Kecamatan Kempas Kabupaten Indragiri Hilir, khususnya pada siswa kelas IV mata pelajaran Ilmu Pengetahuan Sosial (IPS). Penelitian ini dilakukan dalam 2 siklus. Siklus pertama dilaksanakan dalam 2 kali pertemuan dimana dua kali pertemuan menyampaikan materi pembelajaran sesuai RPP serta 1 kali pertemuan ulangan akhir siklus. Siklus kedua juga dilaksanakan dalam 2 kali pertemuan, yaitu dua kali pertemuan, menyampaikan materi pembelajaran sesuai RPP serta 1 kali pertemuan ulangan akhir harian. Ulangan akhir siklus dilaksanakan dalam penelitian ini untuk mengetahui peningkatan hasil belajar siswa kelas IV SDN 005 Kempas Jaya Kecamatan Kempas Kabupaten In dragiri Hilir, dari skor dasar sampai dengan siklus kedua. Sedangkan untuk mengamati aktivitas guru dan aktivitas siswa selama proses pembelajaran dengan menerapkan pembelajaran daring dengan hasil observasi terlihat pada tabel 1 di bawah.

Tabel 1. Aktivitas Guru Pada Setiap Pertemuan Siklus Pertama dan Siklus Kedua

\begin{tabular}{ccccc}
\hline No & \multicolumn{2}{c}{$\begin{array}{c}\text { Siklus pertama } \\
\text { Pertemuan ke }\end{array}$} & \multicolumn{2}{c}{$\begin{array}{c}\text { Siklus kedua } \\
\text { Pertemuan ke }\end{array}$} \\
\hline & 1 & 2 & 1 & 2 \\
\hline 1 & $76 \%$ & $76.16 \%$ & $80.33 \%$ & $85.5 \%$ \\
\hline
\end{tabular}

Berdasarkan tabel di atas dapat diketahui bahwa aktivitas guru dalam pembelajaran daring pada siklus I pertemuan 1 dengan hasil $76 \%$ meningkat pada pertemuan kedua $76.16 \%$, pada siklus II dengan persentase kegiatan pada pertemuan pertama sebesar $80.33 \%$ meningkat menjadi $85.5 \%$ pada pertemuan kedua. Terlihat aktivitas guru yang dilakukan dalam pembelajaran daring pada mata pelajaran IPS dengan dilakukan ujian ulangan dengan hasil belajar terlihat pada tabel 2 di bawah ini.

Tabel 2. Hasil belajar IPS siswa kelas IV SDN 005 Kempas Jaya

\begin{tabular}{|c|c|c|c|c|}
\hline \multirow[t]{2}{*}{ No } & \multirow[t]{2}{*}{ Hasil belajar siswa } & \multirow[t]{2}{*}{ Nilai rata-rata } & \multicolumn{2}{|c|}{$\begin{array}{c}\text { Peningkatan hasil } \\
\text { belajar siswa }\end{array}$} \\
\hline & & & $\mathrm{SD}-\mathrm{UH}_{1}$ & $\mathrm{UH}_{1}-\mathrm{UH}_{\mathrm{II}}$ \\
\hline 1 & Skor dasar & 56.53 & & \\
\hline 2 & Ulangan akhir siklus I & 65.77 & $16.34 \%$ & $22.11 \%$ \\
\hline 3 & Ulangan akhir siklus II & 69.03 & & \\
\hline
\end{tabular}

Pada tabel di atas dapat terlihat hasil belajar IPS siswa dengan menerapkan pembelajaran daring mengalami peningkatan, yang dimulai dari skor dasar atau sebelum menerapkan pembelajaran daring rata-rata hasil belajar IPS yang diperoleh siswa hanya 56.53, pada ulangan akhir siklus pertama nilai rata-rata hasil belajar siswa meningkat akhir siklus pertama nilai ratarata hasil siswa meningkat menjadi 65.77 dengan peningkatan 9.24 poin. Bila diperhatikan kondisi hasil belajar siswa pada skor dasar dan ulangan akhir siklus pertama, karena siswa masih belum terbiasa dengan menerapkan pembelajaran daring karena pembelajaran ini lebih memberikan kesempatan kepada siswa untuk mampu menggunakan teknologi berupa smartphone sebagai alat pembelajaran. Sementara itu pada ulangan akhir siklus kedua, nilai rata-rata hasil belajar siswa meningkat menjadi 69.03 dengan peningkatan sebesar 12.5 poin. Terjadi peningkatan hasil belajar siswa dengan menerapkan pembelajaran daring.

Guru berperan penting dalam pelaksanaan pembelajaran di sekolah, perannya tidak hanya sebatas dalam mengajar tapi juga bagaimana mendidik siswa agar memiliki kemampuan 
intelektual yang tinggi, kecakapan dalam melakukan aktivitas terkait pembelajaran, dan memiliki sikap yang positif baik bagi dirinya maupun orang lain. Semua ini merupakan tanggung jawab guru yang merupakan profesional dalam bidang pendidikan (Usman, 2002; Helen, 2021). Peran orang tua juga sangat menentukan di dalam pembelajaran daring ini hal ini berkaitan dengan pendapat Mooekbun, dkk (2018) mengatakan bahwa pola asuh adalah interaksi antara anak dan orang tua selama mengadakan kegiatan pengasuhan yang berarti orang tua mendidik, membimbing dan mendisiplinkan serta melindungi anak sehingga memungkinkan anak untuk mencapai tugas-tugas perkembangannya.

Pembelajaran yang idealnya dilakukan secara tatap muka akan tetapi pandemik yang saat ini (Rusli, 2021). Kegiatan pembelajaran yang biasanya tatap muka diubah menjadi pembelajaran jarak jauh berupa pembelajaran daring (dalam jaringan/ online), hal ini mengacu dari surat edaran yang dikeluarkan oleh Kementrian Pendidikan dan Kebudayaan (Kemendikbud) Direktorat Pendidikan Tinggi No 1 tahun 2020. Sehingga menuntut guru dan siswa harus menguasai teknologi untuk menggunakan aplikasi sebagai pembelajaran daring. Setelah dilakukan penelitian tindakan kelas dengan menggunakan pembelajaran daring ini terlihat peningkatan hasil belajar yang pertama siswa masih canggung dalam menggunakan aplikasi daring sehingga terhambat dalam pembelajaran yang biasanya secara on time akan tetapi untuk pertama guru memberikan penjelasan dulu sehingga terganggu jam pembelajaran. Seiring dengan waktu siswa sudah mulai terbiasa dengan penggunaan aplikasi daring serta mulai mampu menyimak dengan baik.

\section{SIMPULAN DAN REKOMENDASI}

Kesimpulan dalam penelitian ini adalah bahwa pembelajaran daring dalam meningkatkan hasil belajar siswa dalam mata pelajaran IPS mengalami peningkatan dalam aktivitas guru dan hasil belajar siswa sesuai dengan hasil penelitian yang sudah dilakukan dengan pelaksanakan penelitian tindakan kelas. Saran dalam penelitian ini siswa harus memiliki smartphone yang mampu mengaplikasikan pembelajaran daring serta paket internet yang cukup lumayan mengambil kuota apabila pembelajaran dengan berjam-jam, maka untuk mengatasi permasalahn itu dikurangi jam efektif belajar tidak sesuai dengan jam tatap muka.

\section{DAFTAR PUSTAKA}

Azimah, R., \& Kurniaman, O. (2019). Implementasi Gerakan Literasi Sekolah dalam Pembelajaran di Kelas Tinggi. Jurnal PAJAR (Pendidikan dan Pengajaran), 3(4), 934-947.

Arikunto, S. (2009). Metodologi Penelitian (edisi revisi). Yogyakarta: Bina Aksara

Buchori, A., \& Setyawati, R. D. (2015). Development Learning Model Of Charactereducation Through E-Comic In Elementary School. International Journal of Education and Research, 3(9), 368- 386.

Borg, W. R., \& Gall, M. D. (1983). Educational research: An introduction.

Cahyani, A.G., Ismaya, E.A., \& Fajrie, N. (2021). Family Parenting in Motivating Children during Online Learning. Jurnal PAJAR (Pendidikan dan Pengajaran), 5(2), 349-362. DOI http://dx.doi.org/10.33578/pjr.v5i2.8125.

Helen, H. (2021). Improving Teachers' Pedagogic Competence to Implement Problem Based Learning through Peer Teaching. Jurnal PAJAR (Pendidikan dan Pengajaran), 5(2), 468-474. DOI http://dx.doi.org/10.33578/pjr.v5i2.8328.

Mukmin, B. A., \& Zunaidah, F. N. (2018). Pengembangan Bahan Ajar DELIKAN Tematik Berbasis Multimedia Interaktif Untuk Siswa Sekolah Dasar di Kota Kediri. AL IBTIDA: JURNAL PENDIDIKAN GURU MI, 5(2), 145-158. DOI: http://dx.doi.org/ 10.24235/al.ibtida.snj.v5i2.2788.

Mooekbun, N., Laka, M., Beatus, R. S. \& Selfia. (2018). Peran Orang Tua dalam Meningkatkan Motivasi Belajar Peserta Didik. Jurnal EduMatSains, 2(2), 201- 212.

Novianti, R., Puspitasari, E., \& Maria, I. (2021). Parents' Involvement in Children's Learning Activities during the Covid-19 Pandemic. Jurnal PAJAR (Pendidikan dan Pengajaran), 5(2), 384-390. DOI http://dx.doi.org/10.33578/pjr.v5i2.8220. 
Rambe, M. (2019). Pelaksanaan Supervisi Akademik Sebagai Upaya untuk Meningkatkan Kompetensi Guru dalam Menyusun Rencana Pelaksanaan Pembelajaran. Jurnal PAJAR Pendidikan dan Pengajaran),3(4), 782-790.

Rusli. (2021). Efforts to Improve Teachers' Skills in Making Power Point Learning Media through In House Training. Jurnal PAJAR (Pendidikan dan Pengajaran), 5(2), 462-467. DOI http://dx.doi.org/10.33578/pjr.v5i2.8337.

Saputra, S., \& Prasetyono, H. (2020). The Effect of Scientific Approach to the Activity of Learning Students in SMPN 25 Tangerang City. Jurnal PAJAR (Pendidikan dan Pengajaran), 4(1), 20-30.

Usman, M, U. (2002). Menjadi Guru Profesional. Bandung: PT Remaja Rosdakarya.

Yuliati, R. (2008). Ilmu Pengetahuan Sosial. Jakarta : Pusat Perbukuan Departemen Pendidikan Nasional 